\title{
SEXUALLY TRANSMITTED INFECTIONS AMONG ADOLESCENT AND ADULT WOMEN VICTIMS OF SEXUAL VIOLENCE IN THE METROPOLITAN REGION OF SÃO PAULO, BRAZIL
}

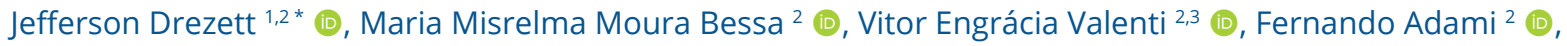 \\ Luiz Carlos de Abreu 2,4 (1) \\ 1 Departamento de Saúde, Ciclos de Vida e Sociedade. Faculdade de Saúde Pública da Universidade de São Paulo. São Paulo, Brazil. \\ ${ }^{2}$ Laboratório de Delineamento de Estudos e Escrita Científica da Faculdade de Medicina do ABC. Santo André, Brazil. \\ ${ }^{3}$ Departamento de Fonoaudiologia da Universidade Estadual de São Paulo. Marília, Brazil. \\ ${ }^{4}$ Graduate Entry Medical School. University of Limerick. Limerick, Ireland.
}

\begin{abstract}
Background: Sexual violence is a serious violation of human rights that mainly affects women. Among the impacts on health, sexually transmitted infections (STIs) are important due to their high prevalence and possible reproductive harm. Objective: To check and compare the incidence of STIs in adolescent and adult women victims of sexual violence. Method: Retrospective cohort study with 135 adolescents (10-19 years) and 154 adult women ( $\geq 20$ years) attending the Pérola Byington Hospital, São Paulo, Brazil, with vaginal and/or anal unprotected exposure during the sexual crime, with ingression between 72 hours and 10 days of the violence, who did not receive prophylaxis for STIs, hepatitis B or HIV. Cases with earlier STIs, pregnant women and violence from an intimate partner were excluded. The outcome was the occurrence of STIs in the two groups. Data were introduced in the program Epi Info6, version 6.04b, with statistical analysis by chi-square test. Results: The diagnosis of STIs occurred for $32.6 \%$ of adolescents and $31.1 \%$ of adult women. The median age was $21.0 \pm 5.8$ years. Adolescents were more vulnerable to the related and known aggressors. Ninety-two patients with STIs (31.8\%) were found along with 120 infections among the 289 women, distributed between HPV (16.9\%), trichomoniasis (6.6\%), chlamydia (3.8\%), herpes $(2.4 \%)$, hepatitis B $(2.4 \%)$, syphilis $(2.1 \%)$, gonorrhea $(1.7 \%)$ pelvic inflammatory disease $(1.7 \%)$, hepatitis C (1.4\%), HIV (1.4\%) and HTLV I and II (1.0\%). Conclusion: The incidence and distribution of STIs show no differences in the two groups, suggesting similar risk for adolescent and adult women when submitted to the same forms of exposure during sexual crime.
\end{abstract}

Keywords: Sex offences, Adolescent, Sexually transmitted diseases, HIV infections, Clinical laboratory techniques, Crime victims.

\section{Introduction}

Sexually transmitted infections (STIS) are considered a public health problem. The World Health Organization (WHO) estimates that in 2018 there were 376 million new cases of chlamydia, gonorrhoea, syphilis and trichomoniasis. More than 500 million people are estimated to have genital herpes simplex virus and 290 million women have a human papillomavírus infection. A further one million cases of viral STIs were diagnosed in the same period, generating considerable economic costs for the health system. ${ }^{1}$

STIs have consequences that may impair the sexual and reproductive health of women, related to ectopic pregnancy and anogenital cancer. ${ }^{1}$ Between $10 \%$ and $40 \%$ of young women with untreated gonococcus or chlamydia infection develop pelvic inflammatory disease (PID), which in almost $25 \%$ of cases can result in infertility by tuboperitoneal factor. ${ }^{1}$

There is enough evidence associating STIs with unsafe sexual behaviours or vulnerable situations. ${ }^{2}$ In recent decades, there has been growing interest in the link between STIs and sexual crimes. ${ }^{3}$ Sexual violence is a global problem of

Funding: The authors received no financial support for the research, authorship, and/or publication of this article.

Disclosure statement: No potential conflict of interest was reported by the authors.

Received: 06/03/2020

Accepted: $11 / 03 / 2021$

Study carried out at Pérola Byington Hospital, São Paulo, Brazil

Copyright Drezett et al. This is an Open Access article distributed under the terms of the Creative Commons Attribution License, which permits unrestricted use, distribution, and reproduction in any medium, provided the original work is properly cited. 
enormous magnitude and rapid growth, defined by the WHO as any sexual act attempted or consummated without the consent of the victim, perpetrated through coercive or intimidating means, with use of force, threat, weapons or psychological fear. ${ }^{4}$

Within the context of violence in large urban centres, the most frequent victims of sexual violence are young women or teenagers, white, unmarried, poorly educated, often approached by unknown offenders in public spaces during daily activities. $^{5}$

On the other hand, it is estimated that between $10 \%$ and $50 \%$ of women suffer some kind of physical, sexual or psychological violence committed by an intimate partner at some point in their lives. ${ }^{6}$ Sexual crimes against children also tend to occur in private, usually intrafamily environments, mainly involving known offenders, often with kinship with the child or with privileged access to their routine. ${ }^{7}$

Sexual violence is considered to be the extreme restriction of sexual and reproductive autonomy of women. STIs are one of its consequences, affecting a significant proportion of women with varying prevalence of each aetiologic agent. 2,8 However, the incidence of STIs is not clear in sex crimes.

There is little information on the prevalence of STIs among adult men who practise sex crimes, and that is limited to the populations of convicted men. ${ }^{9}$ Furthermore, the diagnosis of STIs does not differentiate infections resulting from sexual violence from those pre-existing in sexually active women. Thus, most studies have mainly contributed to prevalence data. ${ }^{8}$

Information on the incidence and prevalence of STIs among adolescents in sexual violence situations is less common. Several studies that include children and adolescents in their analyses are based on their common condition of vulnerability and need for legal protection. However, children are less subjected to sexual offences with acts of penetration than teens, causing less exposure to STIs. ${ }^{10}$

Other studies with adolescents do not distinguish sexual abuse cases with prolonged or repeated exposure to STIs with the same offender, which can modify its prevalence. The objective is to describe and compare the incidence of STIs among adolescents and adult women exposed to a single episode of sexual violence.

\section{Method}

\section{Study Design}

This is a retrospective cohort study of 289 female patients, from the metropolitan area of São Paulo, who have suffered sexual violence. The study was carried out at the Department of Legal Abortion and Sexual Violence at the Pérola Byington Hospital, São Paulo, Brazil, between August 2004 and December 2015. The convenience sample was divided into two groups, with 135 adolescents (aged $\geq 10$ and $<20$ years) and 154 adult women (aged $\geq 20$ years).

\section{Selection and inclusion of research subjects}

Inclusion criteria were 1) the exposure to semen or other biological material potentially infected with human immunodeficiency virus (HIV) from an offender of unknown status, and 2) time to service after 72 hours and before completing 10 days after the sexual crime. We considered only single-sex crimes and acts of vaginal and/or anal penetration, and not those associated with oral exposure. The included patients did not receive prophylaxis for bacterial sexually transmitted infections (STIS), hepatitis B or HIV, because they arrived after the limit time recommended by the National STIs and AIDS Programme. ${ }^{2}$ The criterion used to establish the sex crime was the claim of the patient or her legal representative consistent with Articles 213 and 217-A of the Brazilian criminal law. The Article 213 typifies as sexual violence unauthorized sexual contact in which the perpetrator employs the violence or the serious threat to its imposition. The Article 217-A addresses the sexual violence of vulnerable persons, including sexual acts against persons under 14 years of age or persons of any age who cannot offer valid resistance or consent to the sexual act. ${ }^{2}$

\section{Exclusion criteria}

The following were excluded: women and adolescents with at least one STIs diagnosed at admission between 72 hours and 10 days, pregnant women, cases of chronic or repeated sexual assault by the same perpetrator, sex crimes committed by intimate partners, condom used during the sexual abuse, patients previously vaccinated against hepatitis $B$, injecting drug users, and patients with at least one condom failure in the case of resumption of sexual activity during the six-month investigation. 


\section{Laboratory investigation}

Cervical and vaginal samples were collected for a search for gonococcus, chlamydia and trichomonas on admission, and six weeks and three months after sexual violence. Samples for serological investigation of syphilis, HIV, human T-cell lymphotropic virus (HTLV) I and II, and hepatitis B and C were taken on admission. After six weeks, tests for syphilis and HIV were repeated. Three months after sexual violence a new syphilis serology investigation was conducted for HIV, HTLV, and hepatitis B and C. At six months of follow-up, tests for HIV, HTLV, and hepatitis B and C were repeated. For HPV, a Pap smear was performed at baseline and six months after sexual violence. The colposcopic examination was used at baseline and at three and six months after the sexual crime, with a biopsy of the lower genital tract held by abnormal colposcopic presence. Other STIs that may be identified by Pap smear were considered.

Laboratory investigations of STIs exams were routinely employed in the institution. For the diagnosis of syphilis, the Venereal Disease Research Laboratory (VDRL) test and the Fluorescent Treponemal Antibody Absorption test (FTAAbs) were used. The herpes infection was diagnosed from a Pap staining scraped from the vesicles. For gonococcus, a cervical smear was performed for identification of gram-negative diplococci and culture medium modified ThayerMartin. For chlamydia, we used direct immunofluorescence and trichomoniasis direct examination of the vaginal contents. Positive biomarkers HBsAg, anti-HBc IgM and HBeAg were considered for the diagnosis of acute hepatitis B infection. Hepatitis C and HTLV were surveyed by serology. Enzime Linked Immunosorbent Assay (Elisa) was used to search for HIV. Positive samples were confirmed by a second immunoassay and Western blot test. Pelvic inflammatory disease (PID) with no aetiologic agent identified was characterized according to the criteria of the National STIs and AIDS Programme. ${ }^{2}$

\section{Outcome variables}

The outcome was the occurrence of STIs in both age groups, based on the classification of the National STIs and Aids Programme. ${ }^{2}$ We considered cases of infection such as syphilis, trichomoniasis, chlamydia, human papillomavirus (HPV), herpes, gonococcus, HTLV I and II, HIV, PID and hepatitis B and C.

\section{Instrument and data computerization}

The data of interest for the study were extracted from standardized medical records and entered into Epi Info6, version 6.04b. Data consistency was confirmed by double entry verification, comparison of files and correction of discrepancies.

\section{Statistical analysis}

The individual STIs frequency was calculated and compared for each age group, based on the total number of adolescents and women exposed by looking up the possibility of more than one STIs occurring with the same patient. Frequency tables were constructed for data analysis by applying Pearson's chi-square $\left(\chi^{2}\right)$ hypothesis test, fixing the level of rejection of the null hypothesis at $0.05(p \leq 0.05)$. Odds ratio was used to associate the presence of STIs with each age group, with a Confidence Interval $(\mathrm{Cl})$ of $95 \%$.

\section{Ethical aspects}

All patients received medical, social and psychological counselling about STIs and sexual violence, instructed and encouraged to use male or female condoms in all sexual relations until the end of the investigation. Access to condoms was unrestricted and free. Resolutions No. 196/1996 and No. 466/12 of the National Health Council (CNS) were observed regarding the ethical aspects inherent to the conduct of research involving human beings. The database did not incorporate any elements that would allow the identification of patients. The study was approved by the Research Ethics Committee of the Pérola Byington Hospital, protocol n0 034/11, in September 2011.

\section{Results}

The 289 women studied accounted for $25.8 \%$ of the total 1,118 cases of sexual violence treated in the period, applying the inclusion and exclusion criteria. The mean age was 21.0 (SD 5.8) years. In the group of adult women, ages ranged between 20 and 62 years, with a mean of 26.5 years. Among adolescents, the mean age was 15.6 years. A comparison of the type of exposure to STIs among adolescents and adult women, according to the type of sexual act committed during the crime, is shown in Table 1. The incidence and frequency of STIs are described in Table 2. 
Table 1. Type of sexual act with penetration practiced by the perpetrator against adolescent and adult women victims of single episode of sexual violence, metropolitan area of São Paulo

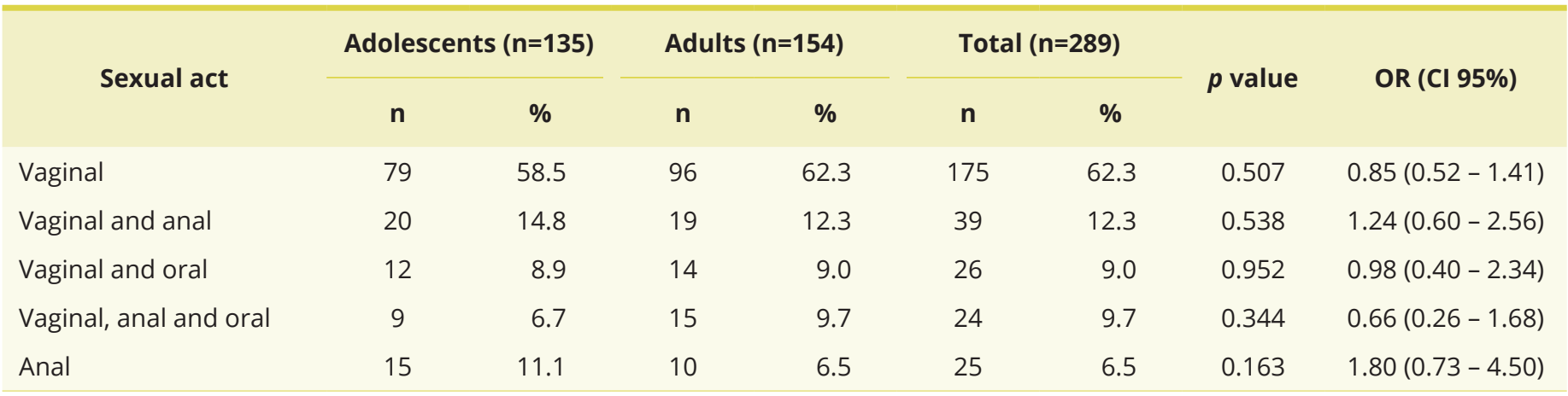

Table 2. Prevalence of diagnosed sexually transmitted infections calculated for the total of adolescent and adult women victims of sexual violence, metropolitan area of São Paulo

\begin{tabular}{|c|c|c|c|c|c|c|c|c|}
\hline & \multicolumn{2}{|c|}{ Adolescents $(n=135)$} & \multicolumn{2}{|c|}{ Adults ( $n=154)$} & \multicolumn{2}{|c|}{ Total $(n=289)$} & \multirow{2}{*}{$p$ value } & \multirow{2}{*}{ OR (CI 95\%) } \\
\hline & $\mathbf{n}$ & $\%$ & $\mathbf{n}$ & $\%$ & $\mathbf{n}$ & $\%$ & & \\
\hline Diagnosed STI & 44 & 32.6 & 48 & 31.1 & 92 & 31.8 & 0.795 & $1.07(0.63-1.81)$ \\
\hline \multirow{2}{*}{ STI } & \multicolumn{2}{|c|}{ Adolescents ( $n=135)$} & \multicolumn{2}{|c|}{ Adults ( $n=154)$} & \multicolumn{2}{|c|}{ Total $(n=289)$} & \multirow{2}{*}{$p$ value } & \multirow{2}{*}{$\mathrm{Cl} 95 \%$} \\
\hline & n & $\%$ & $\mathbf{n}$ & $\%$ & $\mathbf{n}$ & $\%$ & & \\
\hline HPV & 23 & 17.0 & 26 & 16.9 & 49 & 16.9 & 0.972 & $1.01(0.52-1.95)$ \\
\hline Trichomonas & 11 & 8.1 & 8 & 5.2 & 19 & 6.6 & 0.312 & $1.62(0.58-4.57)$ \\
\hline Chlamydia & 4 & 2.9 & 7 & 4.5 & 11 & 3.8 & 0.403 & $0.64(0.15-2.51)$ \\
\hline Herpes & 3 & 2.2 & 4 & 2.6 & 7 & 2.4 & 0.836 & $0.85(0.15-4.60)$ \\
\hline Hepatitis B & 2 & 1.5 & 5 & 3.2 & 7 & 2.4 & 0.330 & $0.45(0.06-2.66)$ \\
\hline Syphilis & 2 & 1.5 & 4 & 2.6 & 6 & 2.1 & 0.506 & $0.56(0.07-3.64)$ \\
\hline Gonococcus & 3 & 2.2 & 2 & 1.3 & 5 & 1.7 & 0.548 & $1.73(0.23-15.00)$ \\
\hline PID & 2 & 1.5 & 3 & 1.9 & 5 & 1.7 & 0.761 & $0.76(0.09-5.66)$ \\
\hline HIV & 1 & 0.7 & 3 & 1.9 & 4 & 1.4 & 0.380 & $0.38(0.01-4.10)$ \\
\hline Hepatitis C & 1 & 0.7 & 3 & 1.9 & 4 & 1.4 & 0.380 & $0.38(0.01-4.10)$ \\
\hline HTLV I & 0 & 0 & 3 & 1.9 & 3 & 1.0 & 0.103 & $0.00(0.00-2.54)$ \\
\hline Total STIs* & 52 & - & 68 & - & 120 & - & & \\
\hline
\end{tabular}

* One or more STIs per adolescent or adult woman, STI: Sexually transmitted infections, 95\% Cl: Confidence Interval of 95\%, HPV: Human Papillomavirus, PID: Pelvic inflammatory disease, HIV: Human immunodeficiency virus, HTLV I: T-cell lymphotropic virus type I human

\section{Discussion}

The occurrence of sexually transmitted infections (STIs) in sex crimes depends on different factors such as the type and frequency of exposure, the occurrence of genital lesions, age and susceptibility of the victim, hymenal rupture of the membrane, HIV status or viral load of the perpetrator, exposure to sexual secretions or blood, or presence of inflammatory STIs or genital ulcer at the time of violence. ${ }^{2}$

Vaginal penetration is described as the act most frequently practised in sexual crimes against women of reproductive age. ${ }^{11}$ In this study, the types of sex acts performed showed similar prevalence in both age groups, indicating equivalent exposure to STIs and similar risk of genital lesions. Forced vaginal penetration also exposes women of reproductive age to unwanted pregnancy. In such cases, the STIs can bring additional complications for both the woman and the foetus, 
including abortion, premature labour, premature rupture of membranes, chorioamnionitis, low birth weight, growth restriction, foetal death, or infection and neonatal death. ${ }^{12}$

In the USA, between 2004 and 2006, 105,000 emergency room visits were made by young women with physical injuries resulting from sexual violence, with 27,000 cases between the ages of 10 and 14 years. ${ }^{13}$ However, studies differ on the frequency of genital lesions among women who suffer sexual violence, with findings from $5 \%$ to $65 \%$, depending on the classification used. The same occurs with extragenital damages present between $10 \%$ and $80 \%$ of cases. ${ }^{14,15}$

Women who suffer sexual violence at the hands of strangers in urban centres are usually constrained by serious threat, and the common use of cold weapons or firearms. ${ }^{16}$ In those circumstances, the threat of death can inhibit women's resistance, leading to the occurrence of physical damage. ${ }^{17}$ Yet genital damage may disrupt the integrity of the genital tissues, causing the inoculation of STIs. ${ }^{10}$ This risk is also considered for virgin women at the time of sexual crime, when the vaginal penetration breaks the hymenal membrane. ${ }^{18}$

Moreover, the frequency of genital trauma among virgin females who suffer sexual crime is 2.5 times higher than among those who are sexually active. ${ }^{17}$ Furthermore, there is evidence that the loss of virginity in forced and violent conditions may impose more serious emotional sequelae. ${ }^{19}$ Cases of intrafamiliar sexual violence committed by known perpetrators show a greater tendency for under-reporting, limiting attendance at health services..$^{15}$ Under those conditions, prophylaxis and diagnosis of STIs are postponed, exposing the different injuries and damages to reproductive health. ${ }^{16}$

In Seattle, USA, research with adult women and adolescents who were treated within 72 hours of sexual violence compared cervicovaginal samples collected at baseline and after two weeks. Controlling the cases considered prior to violence found $4.2 \%$ of positive tests for gonococcus and chlamydia and $1.5 \%$ to $12.3 \%$ for trichomonas. ${ }^{8}$ The most common STIs reported in sexual assault are those that are common in the population and include Chlamydia trachomatis and Neisseria gonorrhoeae. ${ }^{20}$

Further investigation with young women corroborate these observations, with findings ranging between $0.8 \%$ and $9.6 \%$ for gonococcus, $1.5 \%$ and $26 \%$ for chlamydia and $2.1 \%$ and $22 \%$ for trichomonas, similar to that observed in this study. ${ }^{5,18}$ In France, a study of victims of sexual violence detected 3\% of cases with co-infection. ${ }^{21}$ A study in the city of Rio de Janeiro of adolescents at poverty and social risk found 19\% of girls aged 11-14 had a history of violence or sexual exploitation, with $22 \%$ of them having STIs. ${ }^{22}$

The transmission of gonococcus is $50 \%$ by sexual intercourse, with a prevalence of $0.9 \%$ among Brazilian women and $1.5 \%$ among pregnant women. ${ }^{2}$ There is a direct relationship between infertility and tuboperitoneal damage caused by ascending vaginal and cervical infections. The main agents of pelvic inflammatory disease (PID) are Chlamydia trachomatis and Neisseria gonorrhoeae. ${ }^{23} \mathrm{~A}$ case-control study in Rwanda found that a history of sexual violence, being seropositive for human immunodeficiency virus (HIV) infection and genital herpes or chlamydia were predictive factors for tubal factor infertility. ${ }^{24}$

Among adult women who suffer sexual violence, the incidence of human papillomavirus (HPV) varies between $2 \%$ and $40 \% .8,18,25$ A longitudinal study, controlled and randomized with 665 young American women who had suffered sexual violence in the previous 12 months, showed a 4.5 times greater chance of testing positive for HPV 16 or 18 in the cervix, suggesting sexual violence as a risk factor for infection. ${ }^{26}$ The current 2015 Centers for Disease Control and Prevention (CDC) has updated their recommendations for sexually assaulted patients to now receive the HPV vaccine. ${ }^{27}$

While some authors do not check cases of HIV infection in situations of sexual violence, others have found positive HIV tests. ${ }^{8,18}$ The frequency of transmission is low, given that the risk of HIV transmission in consensual sex is $0.1 \%$ to $0.2 \%$ for vaginal and $0.5 \%$ to $3 \%$ for receptive anal intercourse. HIV prophylaxis should be recommended as per the HIV postexposure prophylaxis guidelines from the CDC when there is genital or anal penetration with known ejaculation, especially if trauma occurred. ${ }^{28}$ One can assume that these risks are greater when sex is not consensual and accompanied by violence by the largest association with clinical or subclinical genital lesions.

In South Africa, the results of positive HIV tests performed by 1,435 women who experienced sexual violence increased from $0.9 \%$ to $6.4 \%$ between the years 2001 and 2005, with the highest frequency of cases among women from 16 to 20 years of age. ${ }^{29}$ In this sense, the convergence between HIV and sexual violence has a particular impact on vulnerable populations, such as those in which armed conflict occurs. Supervie et al. (2010) ${ }^{30}$ estimate that about 20,000 women and girls in Uganda are infected with HIV each year as a result of rape, which even qualifies as a serious war crime..$^{30}$

Infection by herpes viruses (HSV) can occur in about $5 \%$ of cases of sexual assault. ${ }^{18}$ The majority of genital infections are caused by HSV-2, although virus type 1 can also cause the infection. The prevalence of antibodies to anti-HSV-2 reaches $30 \%$ of American women, although only $5 \%$ of them report genital lesions. ${ }^{31}$ The percentage of antibodies to HSV-2 among Brazilian pregnant women ranges from $22 \%$ to $42 \%$, but genital manifestation of the disease is found in only $11 \%$ of cases. ${ }^{2}$

There are a few references to infection by HTLV in women in situations of sexual violence..$^{32}$ The viral tropism for $T$ lymphocytes leads to lymphopenia and consequent inversion of the CD4/CD8 ratio. After two to three decades of 
incubation, a minority of infected people may develop complications. ${ }^{2}$ The HTLV I is associated with T-cell leukaemia in adults, tropical spastic paraparesis and myelopathy associated with HTLV I. The implication of HTLV II with human disease is not fully understood, although it is associated with T-cell lymphoma and neurological diseases. ${ }^{2}$

The main known mode of transmission of HTLV is through sex from men to women, through the lymphocytes present in the semen. ${ }^{33}$ The prevalence of antibodies to anti-HTLV I and II in the Brazilian urban population varies between $0.15 \%$ and $2 \%$, reaching $13 \%$ in certain indigenous populations in the Amazon. However, there is no information about its prevalence among sex offenders. ${ }^{2}$

Syphilis remains a systemic disease of global importance, with a prevalence of about $4 \%$ in the general population and $2 \%$ among Brazilian pregnant women. ${ }^{2}$ Treponema pallidum can be diagnosed in between $1 \%$ and $12 \%$ of women who suffer sexual offences. ${ }^{8}$ Transmission by sexual intercourse is $60 \%$ when the offender has hard chancre or flat condyloma. ${ }^{2}$ In Uganda, infection by Treponema pallidum can achieve higher percentages, reaching almost $4 \%$ of victims. ${ }^{34}$ In Mozambique, the prevalence of HIV and syphilis among pregnant women reached $12.2 \%$ and $2.9 \%$, respectively, with $8.4 \%$ of cases having a history of sexual violence. ${ }^{35}$

Among 105 men convicted of sexual offences, $6.5 \%$ had a positive serology for hepatitis C and $13 \%$ for hepatitis $B .{ }^{9}$ In Brazil there are about two million chronic hepatitis B carriers and three million chronic hepatitis $C$ carriers, most unaware of their condition, which affects directly the continuous transmission of the virus. ${ }^{2}$ However, the prevalence of sex offender carriers of these infections is unknown. Transmission of hepatitis B is found in up to $3 \%$ of victims of sexual violence. ${ }^{18,32,36}$ Sexual transmission of hepatitis $C$ is less frequent, estimated at between 2 and $6 \%$ among steady sexual partners. Less reported in the literature, hepatitis C can be diagnosed in between $1.4 \%$ and $3.0 \%$ of women suffering sexual crimes. ${ }^{18}$

Trichomoniasis is a infection with a risk of transmission of between $60 \%$ and $80 \%$ by sexual intercourse, caused by the flagellated protozoan Trichomonas vaginalis, and can occur in $2 \%-22 \%$ of women in situations of sexual violence. $6,8,18$ Although it is not usual to assign greater importance to this protozoan in other circumstances, in pregnant women who suffer sexual violence it may be related to infection with preterm labour, premature rupture of membranes and low birth weight. ${ }^{12}$

Magalhães et al. ${ }^{37}$ report the case of an 11 -year-old female victim of chronic sexual abuse. The donovanosis is a chronic sexually transmitted infectious caused by the Gram-negative bacteria Klebsiella granulomatis, endemic in tropical and subtropical regions. ${ }^{38}$ The infection is rarely described in the literature in cases of sexual violence.

Infections of two or more concurrent STIs were observed in $18.1 \%$ of adolescents and $41.6 \%$ of adult women in this study, an average of 1.2 STIs among adolescents and 1.4 STIs among adult women, as also noted by Estreich et al. ${ }^{18}$

In recent years there has been an increase in the number of victims of sexual violence who use urban health services early and maintain adherence to follow-up, enabling the prevention, investigation and proper treatment of STIs. . $^{6,38}$ These protective actions for women, although evident, still depend on public policies that effectively change old inadequate practices in health services. In Brussels, Belgium, a recent review of emergency services showed that only $20 \%$ of women have received adequate care after suffering sexual crimes. ${ }^{39}$

The health care of women, children and adolescents in situations of sexual violence requires interdisciplinary teams and institutions prepared to provide foster care, prevention, treatment and rehabilitation., ${ }^{2,40}$

We consider important points of this study the period of data collection, the number of patients involved and the strict criteria of inclusion and exclusion. It is worth mentioning the conduction of the study in a reference institution for women victims of sexual violence. However, the retrospective design of the study limits the external validation of the results. Situations of domestic sexual violence may result in different rates of STIs. It was not possible to adopt molecular methods for the research of HPV, chlamydia and gonococcus, which may have interfered in the results of these infections.

\section{Conclusion}

The distribution and incidence of sexually transmitted infections (STIS) were similar in both age groups, indicating that adolescents and adult women face similar risks when submitted to the same unique forms of unprotected exposure to aggressors. The frequency of STIs found in both age groups did not differ from the variation described in the literature, but particular attention must be given to the cases of infection with human T-lymphotrophic viruses (HTLV) type I diagnosed due to the sparse reports in the literature. 


\section{References}

1. World Health Organization. Report on global sexually transmitted infection surveillance 2018. Geneva: World Health Organization; 2018. 63 p.

2. Brasil. Ministério da Saúde. Secretaria de Vigilância em Saúde. Departamento de Doenças de Condições Crônicas e Infecções Sexualmente Transmissíveis. Protocolo clínico e diretrizes terapêuticas para atenção integral às pessoas com infecções sexualmente transmissíveis. Brasília (DF): Ministério da Saúde; 2019. 248 p.

3. Dunn SF, Gilchrist VJ. Sexual assault. Prim Care. 1993;20(2):359-73. PMid:8395063.

4. World Health Organization. World report on violence and health. Geneva: World Health Organization; 2002.346 p.

5. Teerapong S, Lumbiganon P, Limpongsanurak S, Udomprasertgul V. Physical health consequences of sexual assault victims. J Med Assoc Thai. 2009;92(7):885-90. PMid:19626805.

6. Ellsberg M, Jansen HA, Heise L, Watts CH, Garcia-Moreno C, WHO Multi-country Study on Women's Health and Domestic Violence against Women Study Team. Intimate partner violence and women's physical and mental health in the WHO multi-country study on women's health and domestic violence: an observational study. Lancet. 2008;371(9619):1165-72. http://dx.doi.org/10.1016/ S0140-6736(08)60522-X. PMid:18395577.

7. Sapp MV, Vandeven AM. Update on childhood sexual abuse. Curr Opin Pediatr. 2005;17(2):258-64. http://dx.doi.org/10.1097/01. mop.0000158731.64293.c7. PMid:15800423.

8. Jenny C, Hooton TM, Bowers A, Copass MK, Krieger JN, Hillier SL, et al. Sexually transmitted diseases in victims of rape. N Engl J Med. 1990;322(11):713-6. http://dx.doi.org/10.1056/NEJM199003153221101. PMid:2155389.

9. Giotakos O, Bourtsoukli P, Paraskeyopoulou T, Spandoni P, Stasinos S, Boulougouri D, et al. Prevalence and risk factors of HIV hepatitis B and hepatitis C in a forensic population of rapists and child molesters. Epidemiol Infect. 2003;130(3):497-500. http:// dx.doi.org/10.1017/S0950268803008318. PMid:12825735.

10. Girardet RG, Lahoti S, Howard LA, Fajman NN, Sawyer MK, Driebe EM, et al. The epidemiology of sexually transmitted infections in suspected child victims of sexual assault. Pediatrics. 2009;124(1):79-86. http://dx.doi.org/10.1542/peds.2008-2947. PMid:19564286.

11. Traore Y, Mounkoro N, Teguete I, Djire MY, Diallo A, Bagayogo M, et al. Aspects Cliniques et Medico-Legaux des Agressions Sexuelles au CHU Gabriel Toure. Mali Med. 2010;25(3):27-30. PMid:21441086.

12. Mullick S, Watson-Jones D, Beksinska M, Mabey D. Sexually transmitted infections in pregnancy: prevalence, impact on pregnancy outcomes, and approach to treatment in developing countries. Sex Transm Infect. 2005;81(4):294-302. https://doi.org/10.1136/ sti.2002.004077. PMid:16061534.

13. Gavin L, MacKay AP, Brown K, Harrier S, Ventura SJ, Kann L, et al. Sexual and reproductive health of persons aged 10-24 years - United States, 2002-2007. MMWR Surveill Summ. 2009;58(6):1-58. PMid:19609250.

14. Riggs N, Houry D, Long G, Markovchick V, Feldhaus KM. Analysis of 1,076 cases of sexual assault. Ann Emerg Med. 2000;35(4):35862. http://dx.doi.org/10.1016/S0196-0644(00)70054-0. PMid:10736122.

15. Vertamatti MAF, Strufaldi R, Evans DP, Drezett J, Barbosa CP, Abreu LC. Factors associated with reporting delays and severity of childhood sexual abuse in São Paulo, Brazil. Psychol Health Med. 2019;24(6):739-48. http://dx.doi.org/10.1080/13548506.201 8.1556397. PMid:30539657.

16. Bessa MM, Drezett J, Adami F, Araújo SDT, Bezerra IMP, Abreu LC. Characterization of adolescent pregnancy and legal abortion in situations involving incest or sexual violence by an unknown aggressor. Medicina (Kaunas). 2019;55(8):E474. http://dx.doi. org/10.3390/medicina55080474. PMid:31412605.

17. Biggs M, Stermac LE, Divinsky M. Genital injuries following sexual assault of women with and without prior sexual intercourse experience. CMAJ. 1998;159(1):33-7. PMid:9679484.

18. Estreich S, Forster GE, Robinson A. Sexually transmitted diseases in rape victims. Genitourin Med. 1990;66(6):433-8. http://dx.doi. org/10.1056/NEJM199003153221101. PMid:2265841.

19. Fleming J, Mullen PE, Sibthorpe B, Bammer G. The long-term impact of childhood sexual abuse in Australian women. Child Abuse Negl. 1999;23(2):145-59. http://dx.doi.org/10.1016/S0145-2134(98)00118-5. PMid:10075184.

20. Workowski KA, Bolan GA, Centers for Disease Control and Prevention. Sexually transmitted diseases treatment guidelines, 2015. MMWR Recomm Rep. 2015;64(RR-03):1-137. PMid:26042815.

21. Jauréguy $F$, Chariot $P$, Vessières $A$, Picard $B$. Prevalence of Chlamydia trachomatis and Neisseria gonorrhoeae infections detected by real-time PCR among individuals reporting sexual assaults in the Paris, France area. Forensic Sci Int. 2016;266:130-3. http:// dx.doi.org/10.1016/j.forsciint.2016.04.031. PMid:27261924.

22. Teixeira SAM, Taquette SR. Violência e atividade sexual desprotegida em adolescentes menores de 15 anos. Rev Assoc Med Bras. 2010;56(4):440-6. http://dx.doi.org/10.1590/S0104-42302010000400017. PMid:20835641.

23. Soper DE. Pelvic inflammatory disease. Obstet Gynecol. 2010;116(2 Pt 1):419-28. http://dx.doi.org/10.1097/A0G.0b013e3181e92c54 PMid:20664404.

24. Dhont N, van de Wijgert J, Luchters S, Muvunyi C, Vyankandondera J, Temmerman M. Sexual violence, HSV-2 and HIV are important predictors for infertility in Rwanda. Hum Reprod. 2010;25(10):2507-15. http://dx.doi.org/10.1093/humrep/deq189. PMid:20685757. 
25. Deutsch SA, Benyo S, Xie S, Carlin E, Andalaro B, Clagg B, et al. Addressing Human Papillomavirus prevention during pediatric acute sexual assault care. J Forensic Nurs. 2018;14(3):154-61. http://dx.doi.org/10.1097/JFN.0000000000000209. PMid:30130316.

26. Wingood GM, Seth P, DiClemente RJ, Robinson LS. Association of sexual abuse with incident high-risk human papillomavirus infection among young African-American women. Sex Transm Dis. 2009;36(12):784-6. http://dx.doi.org/10.1097/0LQ.0b013e3181b3567e. PMid:19704392.

27. Scannell M. Centers for Disease Control and Prevention 2015 Human Papillomavirus vaccine recommendations for sexually assaulted patients: a review and update. J Forensic Nurs. 2016;12(4):160-6. http://dx.doi.org/10.1097/JFN.0000000000000126. PMid:27782923.

28. Crawford-Jakubiak JE, Alderman EM, Leventhal JM, Committee on Child Abuse and Neglect, Committee on Adolescence. Care of the adolescent after an acute sexual assault. Pediatrics. 2017;139(3):e20164243. http://dx.doi.org/10.1542/peds.2016-4243. PMid:28242861.

29. Meel B, Kwizera E. Prevalence of HIV in the Mthatha area of South Africa, as estimated from the testing of rape victims. Med Sci Law. 2011;51(2):106-8. http://dx.doi.org/10.1258/msl.2010.010204. PMid:21793474.

30. Supervie V, Halima Y, Blower S. Assessing the impact of mass rape on the incidence of HIV in conflict-affected countries. AIDS. 2010;24(18):2841-7. http://dx.doi.org/10.1097/QAD.0b013e32833fed78. PMid:20859191.

31. Hayward K, Cline A, Stephens A, Street L. Management of herpes zoster (shingles) during pregnancy. J Obstet Gynaecol. 2018;38(7):88794. http://dx.doi.org/10.1080/01443615.2018.1446419. PMid:29565203.

32. Casseb J, Oliveira FI Jr. A possible case of human T-cell lymphotropic virus type I transmission through sexual assault. Sex Transm Dis. 1998;25(6):327-8. http://dx.doi.org/10.1097/00007435-199807000-00011. PMid:9662769.

33. Eusebio-Ponce E, Anguita E, Paulino-Ramirez R, Candel FJ. HTLV-1 infection: An emerging risk. Pathogenesis, epidemiology, diagnosis and associated diseases. Rev Esp Quimioter. 2019;32(6):485-96. PMid:31648512.

34. Ononge S, Wandabwa J, Kiondo P, Busingye R. Clinical presentation and management of alleged sexually assaulted females at Mulago hospital, Kampala, Uganda. Afr Health Sci. 2005;5(1):50-4. PMid:15843131.

35. Cossa HA, Gloyd S, Vaz RG, Folgosa E, Simbine E, Diniz M, et al. Syphilis and HIV infection among displaced pregnant women in rural Mozambique. Int J STD AIDS. 1994;5(2):117-23. http://dx.doi.org/10.1177/095646249400500208. PMid:8031913.

36. van Rooijen MS, Schim van der Loeff MF, van Kempen L, de Vries HJC. Sexually transmitted infection positivity rate and treatment uptake among female and male sexual assault victims attending The Amsterdam STI Clinic between 2005 and 2016. Sex Transm Dis. 2018;45(8):534-41. http://dx.doi.org/10.1097/OLQ.0000000000000794. PMid:29465647.

37. Magalhães BM, Veasey JV, Mayor SAS, Lellis RF. Donovanosis in a child victim of sexual abuse: response to doxycycline treatment. An Bras Dermatol. 2018;93(4):592-4. http://dx.doi.org/10.1590/abd1806-4841.20187948.

38. Vrees RA. Evaluation and management of female victims of sexual assault. Obstet Gynecol Surv. 2017;72(1):39-53. http://dx.doi. org/10.1097/OGX.0000000000000390. PMid:28134394.

39. Gilles C, Van Loo C, Rozenberg S. Audit on the management of complainants of sexual assault at an emergency department. Eur J Obstet Gynecol Reprod Biol. 2010;151(2):185-9. http://dx.doi.org/10.1016/j.ejogrb.2010.03.014. PMid:20378238.

40. McCormack D, Koons K. Sexually transmitted infections. Emerg Med Clin North Am. 2019;37(4):725-38. https://doi.org/10.1016/j. emc.2019.07.009. PMid:31563204.

\author{
*Correspondence \\ Jefferson Drezett \\ Faculdade de Saúde Pública da USP \\ Avenida Dr. Arnaldo 715 \\ CEP 01246-904, São Paulo, SP, Brasil \\ 55 (11) $98182-5434$ \\ jdrezett@gmail.com
}

\title{
Author information
}

Jefferson Drezett: PhD in Health Science. Professor at Department of Health, Life Cycles and Society, School of Public Health, University of São Paulo. Associate Researcher at the Laboratory of Study Design and Scientific Writing of the School of Medicine of ABC. Maria Misrelma Moura Bessa: PhD in Health Science. Researcher at the Laboratory of Study Design and Scientific Writing of the School of Medicine of ABC. Vitor Engracia Valenti: Postdoctoral in Physiopathology. Associate professor at Speech and Hearing Pathology at State University of São Paulo. Associate Researcher at the Laboratory of Study Design and Scientific Writing of the School of Medicine of ABC. Fernando Adami: Postdoctoral in epidemiology. Associate Researcher at the Laboratory of Study Design and Scientific Writing of the School of Medicine of ABC. Luiz Carlos de Abreu: Full Professor. Coordinator of the Laboratory of Study Design and Scientific Writing of the School of Medicine of ABC. Professor in Master in Public Health at Graduate Entry Medical School in The University of Limerick. 


\section{Author Contributions}

The author Jefferson Drezett (author 1) participated in the developed the research question, performed the statistical analysis, interpreted results, provided the tables, and drafted the manuscript. The author Maria Misrelma Moura Bessa (author 2) participated in the interpretation the results, and drafted the manuscript. The author Vitor Engracia Valenti (author 3) participated in the statistical analysis and drafted the manuscript. The author Fernando Adami (author 4) participated in the statistical analysis, and provided the tables. The author Luiz Carlos de Abreu (author 5) participated in the developed the research question, and interpreted results. All authors read and approved the final manuscript.

\section{Abbreviations and Symbols}

STI Sexually transmitted infections

WHO World Health Organization

PID pelvic inflammatory disease

HIV human immunodeficiency virus

HTLV human T-cell lymphotropic virus

VDRL Venereal Disease Research Laboratory

FTAAbs Fluorescent Treponemal Antibody Absorption

ELISA Enzime Linked Immunosorbent Assay

HPV human papillomavirus,

CNS National Health Council

CDC Centers for Disease Control and Prevention

HSV herpes simplex virus

HSV herpes simplex virus 